\title{
Capacitation- and fertilization-related alterations in mouse sperm oxygen consumption
}

\author{
Lynn R. Fraser and M. R. Lane \\ Department of Anatomy and Human Biology, King's College London (KQC), Strand, \\ London WC2R $2 L S, U . K$.
}

\begin{abstract}
Summary. On the basis of experiments performed some years ago, it has been generally accepted that mammalian sperm metabolic activity, as determined by manometric measurement of $\mathrm{O}_{2}$ uptake, increases during capacitation. However, when mouse sperm suspensions were incubated for a total of $120 \mathrm{~min}$ in glucose-containing medium which promotes both capacitation and fertilization, $\mathrm{O}_{2}$ consumption, measured with an $\mathrm{O}_{2}$ electrode at 30 and $120 \mathrm{~min}$, consistently declined with time. This same pattern was also observed when pyruvate was the sole exogenous energy substrate, despite the fact that these cells, although capacitated, cannot fertilize eggs until supplied with glucose. Since mouse spermatozoa require a suitable glycolysable substrate to express full functional ability, these results suggest that a shift in metabolic activity from oxidative phosphorylation to glycolysis normally accompanies the onset of fertilizing ability in this species. It was further demonstrated that this pattern, in the presence of glucose, can be markedly modified by alterations in the medium composition which have been shown to modulate fertilizing ability. All conditions chosen inhibit fertilization while retarding $\left(\mathrm{Ca}^{2+}\right.$-free), accelerating (hyperosmotic high $\mathrm{Na}^{+}$) or nor affecting (iso-osmotic high $\mathrm{K}^{+}$) the rate of capacitation. When suspensions were assessed in these media, $\mathrm{O}_{2}$ consumption increased rather than decreased over the $120 \mathrm{~min}$, despite the continuous presence of glucose. When these same suspensions were assessed at 30 and $120 \mathrm{~min}$ in media altered to permit expression of fertilizing ability, the pattern observed was one of declining $\mathrm{O}_{2}$ consumption. For the condition which accelerated capacitation, the decline relative to the inhibitory medium was seen at both 30 and $120 \mathrm{~min}$, while with the other two, the shift was only observed at $120 \mathrm{~min}$ when suspensions would have obtained some degree of competence. The ionic composition of the extracellular environment therefore markedly affects sperm metabolic activity which in turn may modulate sperm functional ability both in vitro and in vivo.
\end{abstract}

\section{Introduction}

Mammalian spermatozoa are not immediately functional upon release from the male reproductive tract but must undergo further changes, collectively called capacitation, which confer on them potential fertilizing ability. Capacitation normally occurs in the female reproductive tract, although the development of culture systems now makes it possible to manipulate and capacitate spermatozoa from at least some mammalian species in vitro. Given that complete capacitation usually requires several hours (the length being species-dependent; Bedford, 1970), the possibility that changes in sperm metabolic activity might accompany capacitation was examined about 20 years ago in several studies (e.g. Hamner \& Williams, 1963; Mounib \& Chang, 1964; Murdoch \& White, 1967). Comparisons were made between freshly ejaculated rabbit spermatozoa and those which had been incubated in utero for several hours as at least an approximation to capacitation. Since values for the latter group were the higher, it was concluded that metabolic activity, as measured by 
manometric determinations of $\mathrm{O}_{2}$ uptake, increased with capacitation. The development of the $\mathrm{O}_{2}$ electrode has provided an easier, yet accurate, method to measure $\mathrm{O}_{2}$ consumption by cells. Using both this approach and a Cartesian diver to study mouse spermatozoa incubated in vitro, Boell (1985) reported that, in contrast to the above, no time-dependent changes in metabolic activity occurred and that various modifications to the incubation medium failed to alter the rate of $\mathrm{O}_{2}$ consumption. However, the cells were washed before incubation and similar treatment has been shown to accelerate mouse sperm capacitation by removing a surface-associated inhibitory factor (Fraser, 1984); therefore, the washed spermatozoa would not have been uncapacitated at the beginning of assessment.

It is important to know the functional state of spermatozoa at the time of assessment and we have a well-characterized in-vitro fertilization system which provides this information. We have demonstrated, for example, that fertilization but not capacitation in the mouse requires the presence of a glycolysable substrate (Fraser \& Quinn, 1981), while other alterations in medium composition can significantly alter capacitation per se (e.g. Fraser, 1982, 1983). Using this system, $\mathrm{O}_{2}$ consumption, as a measure of oxidative phosphorylation, has been determined in epididymal mouse sperm suspensions incubated under conditions previously shown to modify capacitation and fertilizing ability in specific ways. A preliminary report of this study has been published in abstract form (Fraser \& Lane, 1986).

\section{Materials and Methods}

Media. A modified Tyrode's solution (Fraser, 1983) supplemented with albumin (crystalline BSA at $4 \mathrm{mg} / \mathrm{ml}$; Sigma, Poole, Dorset, U.K.) was used throughout. The composition of complete medium is: $125 \mathrm{~mm}-\mathrm{NaCl}, 25 \mathrm{mM}-$ $\mathrm{NaHCO}_{3}, 2.68 \mathrm{~mm}-\mathrm{KCl}, 1.80 \mathrm{~mm}-\mathrm{CaCl}_{2}, 0.49 \mathrm{~mm}-\mathrm{MgCl}_{2}, 0.36 \mathrm{~mm}-\mathrm{NaH}_{2} \mathrm{PO}_{4}, 5.56 \mathrm{~mm}$-glucose, 100 units penicillin/ $\mathrm{ml}$ and phenol red. In Series I, modified media tested were: (a) glucose-free $+5.56 \mathrm{~mm}$-fructose and (b) glucose-free + $4 \mathrm{mM}$-pyruvate. In all other series, glucose was present but other modifications were made; Series II, calcium-free $\left(\mathrm{CaCl}_{2}\right.$ omitted); Series III, iso-osmotic high potassium ( $\left.27.68 \mathrm{mM}-\mathrm{KCl}, 100 \mathrm{mM}-\mathrm{NaCl}\right)$; Series IV, hyperosmotic high sodium $\left(150 \mathrm{~mm}-\mathrm{NaCl}\right.$ ). All media were gassed with $5 \% \mathrm{CO}_{2}$ (see below).before use.

Sperm suspension. These were prepared as for in-vitro fertilization using mature ( $>8$ weeks) outbred TO male mice (Harlan Olac, Bicester, Oxon, U.K.). One cauda epididymidis from each of 2 males was released into $1 \mathrm{ml}$ medium in a 30-mm culture dish (Sterilin, Teddington, Middx, U.K.) overlaid with autoclaved liquid paraffin (Boots, Nottingham, U.K.). Suspensions were incubated for a total of $120 \mathrm{~min}$, with $\mathrm{O}_{2}$ consumption measurements being made at 30 and $120 \mathrm{~min}$. The gas phase used during incubations was either $5 \% \mathrm{CO}_{2}$ in air or $5 \% \mathrm{CO}_{2}-5 \% \mathrm{O}_{2}-90 \%$ $\mathrm{N}_{2}$. No differences were noted between the 2 mixtures and results have therefore been combined.

$\mathrm{O}_{2}$ consumption measurements. Data were obtained using a Rank oxygen electrode (Rank Brothers, Bottisham, Cambs, U.K.) connected to a Gilson $\mathrm{N}_{2}$ pen recorder (Anachem, Luton, Beds, U.K.) Water maintained at $37^{\circ} \mathrm{C}$ was circulated through the electrode's jacketed chamber and constant stirring by a magnetic flea ensured homogeneous distribution of $\mathrm{O}_{2}$ throughout the contents of the chamber. The zero was set by adding a few grains of sodium dithionite to the chamber containing $700 \mu$ distilled water.

Except as noted, measurements were made by adding $350 \mu \mathrm{l}$ gassed medium to the chamber followed by $350 \mu \mathrm{l}$ sperm suspension. The plunger was inserted to expel air and $\mathrm{O}_{2}$ consumption was monitored for approximately $5 \mathrm{~min}$; there was no obvious alteration in $\mathrm{pH}$, judging by the phenol red coloration. When 2 suspensions were being compared at both 30 and 120 min, these measurements had to be made sequentially since only 1 electrode was available. To avoid any discrepancies introduced by the inevitable delay in making the second measurement for a single time point, the order was reversed in alternate replicates. At the end of each measurement, an aliquant of the sperm sample in the chamber was removed, fixed in buffered formalin and counted in a haemocytometer; this figure was used in calculating $\mathrm{O}_{2}$ consumption. The mean sperm concentration was $1.4 \times 10^{7}$ cells $/ \mathrm{ml}$ (range $0.8-2.2 \times 10^{7} / \mathrm{ml}$ ). Data are presented as $\mathrm{nmol} \mathrm{O}_{2}$ consumed $/ \mathrm{min} / 10^{8}$ cells.

In an earlier study it was shown that the $\mathrm{O}_{2}$ consumption measured in mouse sperm suspensions by this method is associated with oxidative phosphorylation activity; the introduction of oligomycin caused a significant decrease in $\mathrm{O}_{2}$ consumption, indicating that oxidation is tightly coupled to phosphorylation in these sperm cells (Fraser \& Quinn, 1981). This was not repeated for the present study since the methods are essentially the same.

Statistical analysis. Data were analysed using the Friedman two-way analysis of variance (Siegel, 1956) to determine whether $\mathrm{O}_{2}$ consumption altered with time in a consistent manner. This is a ranking test which uses matched samples. 


\section{Results}

\section{Series I: the effect of different exogenous substrates}

Initial measurements were made at both 30 and $120 \mathrm{~min}$ on suspensions incubated in the standard Tyrode's medium containing glucose $(+G)$ as substrate; this medium supports complete capacitation and fertilization (Fraser \& Quinn, 1981). Sixteen replicates were carried out $(\mathbf{N}=16)$. In the next experiments, 2 males were used for each replicate with 1 epididymis from each being released into $1 \mathrm{ml}$ standard Tyrode's and the remaining epididymides being released into $1 \mathrm{ml}$ modified glucose-free medium containing either 4 mM-pyruvate $(+P ; N=3)$ or 5.56 mM-fructose $(+F ; N=3)$. Under these conditions mouse spermatozoa can complete capacitation but cannot fertilize eggs due to inhibition of the acrosome reaction and hyperactivated motility (Fraser $\&$ Quinn, 1981).

In glucose-containing medium a consistent and significant $(P<0.05)$ reduction in the rate of $\mathrm{O}_{2}$ consumption was observed at $120 \mathrm{~min}$ (Fig. 1a). When glucose and pyruvate were compared, a similar decline was noted in both groups (Fig. 1b), while $\mathrm{O}_{2}$ consumption in the presence of fructose was very low and did not change appreciably over 120 min despite a significant decline in the glucose-incubated counterparts (Fig. 1c). Spermatozoa in $+\mathrm{F}$ medium are very sluggish and nonfertilizing until supplied with glucose. These results suggest that during capacitation there is a switch from oxidative to glycolytic metabolism which could explain the obligatory requirement for a suitable glycolytic substrate to support fertilization. As can be seen in Fig. 1 which is a composite of three different experiments, absolute values for $\mathrm{O}_{2}$ consumption varied considerably among groups of replicates. However, all within-replicate observations were made on suspensions from the same mice and it is these within-replicate values that have been used to determine whether a consistent or random pattern was obtained. In all replicates using $+G$ and $+P$, the $\mathrm{O}_{2}$ consumption values at $120 \mathrm{~min}$ were consistently lower than the comparable readings obtained with the same suspensions at $30 \mathrm{~min}$.

\section{Series II: conditions which promote partial capacitation}

Mouse spermatozoa incubated for $120 \mathrm{~min}$ in $\mathrm{Ca}^{2+}$-free $(-\mathrm{Ca})$ medium are non-fertilizing. Upon introduction of $\mathrm{Ca}^{2+}(1.80 \mathrm{~mm})$ they are shown to be partially capacitated: a few spermatozoa are able to fertilize rapidly and the suspensions as a whole require only a maximum of $60 \mathrm{~min}$ rather than 120 min to acquire full functional competence (Fraser, 1987). In the first experiments of
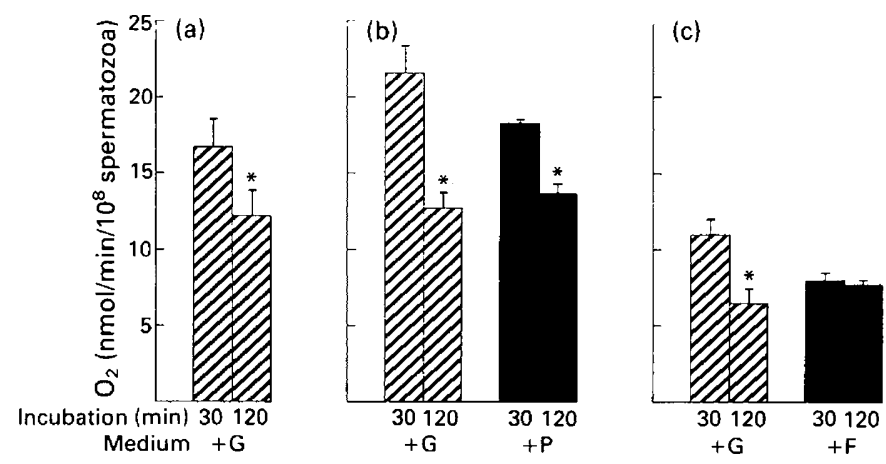

Fig. 1. Oxygen consumption by epididymal mouse sperm suspensions after 30 and 120 min incubation in modified Tyrode's medium containing the following exogenous substrates: (a) glucose $(+G)$; (b) glucose $(+G)$ or pyruvate $(+P)$; (c) glucose $(+G)$ or fructose $(+F)$. Values are mean \pm s.e.m. ${ }^{*} P<0.05$ compared with 30 min suspensions in the same medium. 
this series, a single 2-ml sperm suspension was prepared using - Ca medium and 2 males; $920 \mu l$ of this were transferred to a separate dish and $80 \mu \mathrm{l}$ of a concentrated $\mathrm{Ca}^{2+}$ stock solution $(22.5 \mathrm{mM}$ $\mathrm{CaCl}_{2}$ ) were added to give a final concentration of $1 \cdot 80-\mathrm{mM} \mathrm{Ca}^{2+}(+\mathrm{Ca}) \cdot \mathrm{O}_{2}$ consumption was measured at 30 and $120 \mathrm{~min}$ in the $-\mathrm{Ca}$ and $+\mathrm{Ca}$ suspensions $(\mathrm{N}=4)$. In the second set of experiments, a $2-\mathrm{ml}$ sperm suspension was prepared in - $\mathrm{Ca}$ medium and incubated. At assessment, aliquants of the suspension were added to $-\mathrm{Ca}$ medium or $\times 2 \mathrm{Ca}$ medium, the latter to produce a final $\mathrm{Ca}^{2+}$ concentration of $1.80 \mathrm{~mm}(\mathrm{~N}=3)$.

As observed in Series $\mathrm{I}$, a consistent and significant decline in $\mathrm{O}_{2}$ consumption occurred in suspensions incubated in $+\mathrm{Ca}$ medium; in contrast, a consistent increase was observed in the $-\mathrm{Ca}$ suspensions (Fig. 2a). When suspensions incubated in - Ca medium were assessed both in the absence and presence of $\mathrm{Ca}^{2+}$, the patterns of $\mathrm{O}_{2}$ consumption at 120 min were quite different. As in the first experiments of this series, a significant increase from 30 to $120 \mathrm{~min}$ was noted in $-\mathrm{Ca}$ medium. However, while the introduction of $\mathrm{Ca}^{2+}$ at $30 \mathrm{~min}(-\mathrm{Ca} \rightarrow+\mathrm{Ca})$ caused no obvious consistent alteration in $\mathrm{O}_{2}$ consumption compared with the $30 \mathrm{~min}-\mathrm{Ca}$ suspensions, the same procedure at $120 \mathrm{~min}$, which promotes the onset of fertilizing ability (Fraser, 1982, 1987), caused a consistent and significant decline from the $120 \mathrm{~min}-\mathrm{Ca}$ values and produced a pattern similar to that observed in $+\mathrm{Ca}$ medium (Fig. 2b). Thus alterations in ionic composition which modify fertilizing potential can markedly affect sperm metabolic activity.
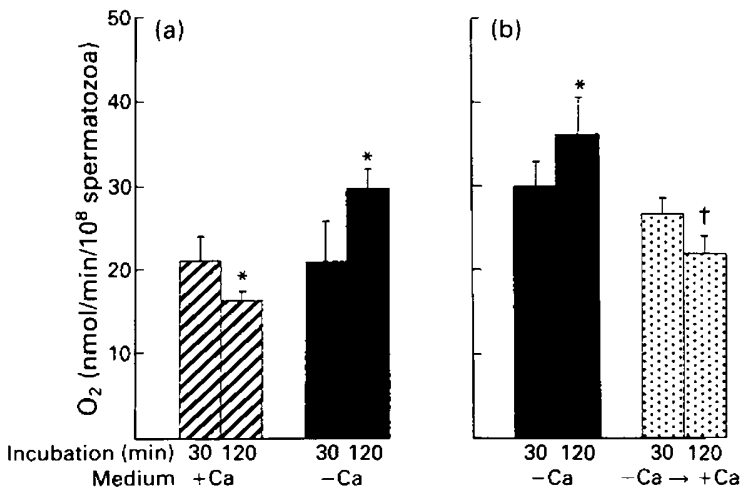

Fig. 2. Oxygen consumption by epididymal mouse sperm suspensions: (a) after 30 and $120 \mathrm{~min}$ incubation in modified Tyrode's medium with $(+\mathrm{Ca})$ or without $(-\mathrm{Ca})$ calcium; $(\mathrm{b})$ after 30 and $120 \mathrm{~min}$ incubation in - $\mathrm{Ca}$ medium and assessed in both $-\mathrm{Ca}$ and $+\mathrm{Ca}$ media. Values are mean \pm s.e.m. ${ }^{*} P<0.05$ compared with 30 min suspensions in the same medium; $\dagger P<0.05$ compared with $120 \mathrm{~min}-\mathrm{Ca}$ suspensions.

\section{Series III: conditions which promote complete capacitation but inhibit fertilization}

Mouse spermatozoa incubated for $120 \mathrm{~min}$ in iso-osmotic high $\mathrm{K}^{+}(27.68 \mathrm{~mm})$ medium are nonfertilizing but essentially completely capacitated since reduction in the $\mathrm{K}^{+}$concentration to $<10 \mathrm{~mm}$ promotes immediate fertilization (Fraser, 1983). In the first set of experiments, $\mathrm{O}_{2}$ consumption was compared in suspensions incubated in standard Tyrode's $\left(2.68 \mathrm{~mm}-\mathrm{K}^{+}\right.$; control $\mathrm{K}$ ) and high $\mathrm{K}(27.68 \mathrm{~mm})$ media. In the second set, single sperm suspensions were prepared and incubated in high $\mathrm{K}$ medium, then assessed in high $\mathrm{K}$ or reduced $\mathrm{K}$ medium. Although ideally the suspensions should have been diluted 10 -fold with $-\mathrm{K}$ medium to reduce the $\mathrm{K}^{+}$to $\sim 2.68 \mathrm{mM}$, this would have lowered the sperm concentration below that required to obtain a reading with the electrode. Consequently, one part of the high $\mathrm{K}$ sperm suspension was added to 2 parts of high $\mathrm{K}$ or $-\mathrm{K}$ medium in the chamber, the latter reducing the $\mathrm{K}^{+}$concentration to $\sim 9 \cdot 2 \mathrm{~mm}$ which does promote fertilization (Fraser, 1983). 
Again there was a consistent decline in $\mathrm{O}_{2}$ consumption over $120 \mathrm{~min}$ in suspensions incubated and assessed in standard Tyrode's with low $\mathrm{K}$. In high $\mathrm{K}$ the reverse was observed, with an increase from 30 to $120 \mathrm{~min}$ (Fig. 3a). When high $\mathrm{K}$ suspensions were assessed in high and reduced $\mathrm{K}$ media, however, the patterns of $\mathrm{O}_{2}$ consumption differed markedly from each other. As in the first part of this series, a significant increase was observed over $120 \mathrm{~min}$ (Fig. 3b). In contrast, while reduction in $\mathrm{K}$ (high $\rightarrow$ reduced $\mathrm{K}$ ) at 30 min caused no consistent alteration in $\mathrm{O}_{2}$ consumption compared with the $30 \mathrm{~min}$ high $\mathrm{K}$ suspensions, reduction at $120 \mathrm{~min}$, which promotes fertilizing ability, produced a consistent and significant decline from the $120 \mathrm{~min}$ high $\mathrm{K}$ values. Thus, as in Series II, conditions that modify fertilizing potential also modify metabolic activity.
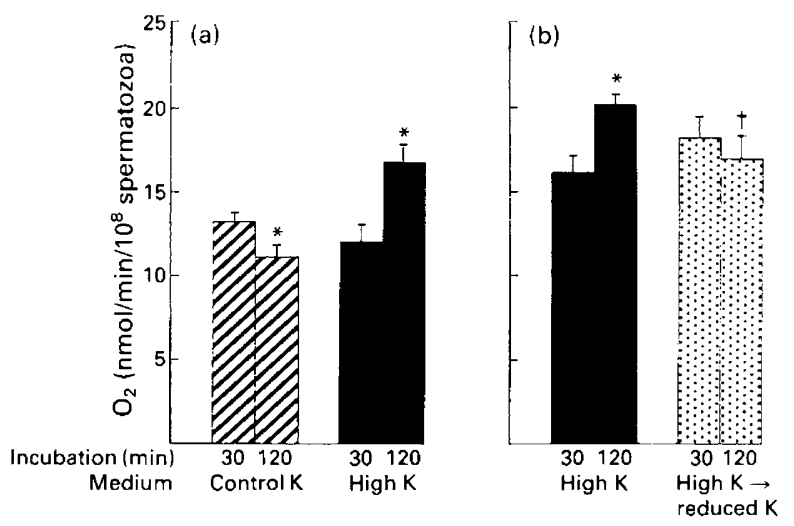

Fig. 3. Oxygen consumption by epididymal mouse sperm suspensions: (a) after 30 and $120 \mathrm{~min}$ incubation in iso-osmotic Tyrode's medium containing potassium at control $\left(2.68 \mathrm{~mm}-\mathrm{K}^{+}\right)$or high $\left(27.68 \mathrm{~mm}-\mathrm{K}^{+}\right)$concentrations; (b) after 30 and 120 min incubation in high $\mathrm{K}$ medium and assessed in high $\mathrm{K}$ and reduced $\mathrm{K}$. Values are mean \pm s.e.m. ${ }^{*} P<0.05$ compared with 30 min suspensions in the same medium; $† P<0.05$ compared with 120 min high $\mathrm{K}$ suspensions.

\section{Series IV: conditions which accelerate capacitation but inhibit fertilization}

Mouse spermatozoa incubated in hyperosmotic high $\mathrm{Na}^{+}(25 \mathrm{mM}$ extra $\mathrm{NaCl})$ medium are nonfertilizing but undergo accelerated capacitation; reduction in the $\mathrm{Na}^{+}$concentration after $30 \mathrm{~min}$ results in significantly higher rates of fertilization than counterparts incubated in standard Tyrode's medium (Fraser, 1983). Furthermore, reduction after $120 \mathrm{~min}$ still promotes high levels of fertilization. In Series IV experiments, single suspensions were prepared and incubated in hyperosmotic medium (high $\mathrm{Na}$ ), then assessed in high $\mathrm{Na}$ or control $\mathrm{Na}(125 \mathrm{~mm}-\mathrm{NaCl})$. For the latter, medium with $100 \mathrm{~mm}-\mathrm{NaCl}$ was prepared so that upon a 1:1 dilution of the high $\mathrm{Na}$ medium the final $\mathrm{NaCl}$ concentration would be $125 \mathrm{~mm}$.

As seen in Series II and III, $\mathrm{O}_{2}$ consumption by sperm suspensions incubated and assessed in conditions which inhibit fertilizing ability increased with time (Fig. 4). By reducing Na which permits expression of fertilizing ability, there was a consistent shift in the $\mathrm{O}_{2}$ consumption pattern to one of decreasing rather than increasing values. This particular manipulation of environmental conditions permits maximal fertilization at both 30 and 120 min (Fraser, 1983) and, as shown in Fig. 4, there was a significant decrease in $\mathrm{O}_{2}$ consumption at both times in response to reduction in $\mathrm{Na}^{+}$. This pattern was not seen in Series II and III, in which functional changes and metabolic changes occurred only in suspensions incubated for $120 \mathrm{~min}$. 


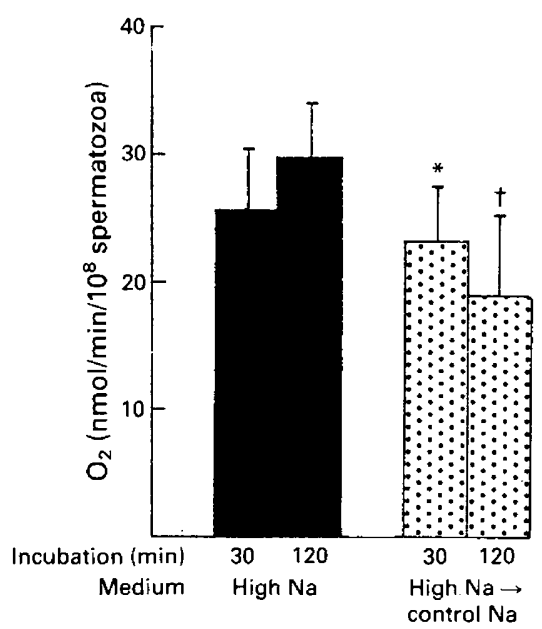

Fig. 4. Oxygen consumption by epididymal mouse sperm suspensions incubated for 30 and $120 \mathrm{~min}$ in hyperosmotic high $\mathrm{Na}(150 \mathrm{~mm}-\mathrm{NaCl})$ medium and assessed in high $\mathrm{Na}$ and control $\mathrm{Na}(125 \mathrm{~mm}-\mathrm{NaCl})$ media. Values are mean \pm s.e.m. ${ }^{*} P<0.05$ compared with 30 min high $\mathrm{Na}$ suspensions; $\uparrow P<0.05$ compared with $120 \mathrm{~min}$ high $\mathrm{Na}$ suspensions.

\section{Discussion}

This study was designed to evaluate $\mathrm{O}_{2}$ consumption by epididymal mouse spermatozoa incubated in conditions which have been shown to promote or inhibit capacitation and/or fertilization. The results indicate that $\mathrm{O}_{2}$ consumption declines during capacitation in vitro in standard Tyrode's medium (glucose-containing). Given that expression of fertilizing ability by capacitated mouse spermatozoa requires a glycolysable substrate such as glucose (Fraser \& Quinn, 1981), this result suggests that there is a shift from oxidative to glycolytic metabolism. A similar pattern of $\mathrm{O}_{2}$ consumption was seen in suspensions incubated in the presence of pyruvate. Functionally, these cells are non-fertilizing, unable to undergo the acrosome reaction and to express hyperactivated motility until supplied with glucose (Fraser \& Quinn, 1981). Despite being a glycolysable substrate, fructose fails to substitute for glucose and $\mathrm{O}_{2}$ consumption is very low (Fig. 1c); the reasons for the inadequacy of fructose may include slower uptake and phosphorylation relative to glucose (Hoppe, 1976). Boell \& Burkus (1984) also noted a low rate of $\mathrm{O}_{2}$ consumption in the presence of fructose, although they reported these cells to be highly motile. We have never observed this (present study; Fraser \& Quinn, 1981) and cannot explain the discrepancy unless it relates to the washing procedure. Certainly mouse spermatozoa cannot fertilize eggs in the presence of fructose alone (Hoppe, 1976; Fraser \& Quinn, 1981). The present results are consistent with the obligatory requirement mouse spermatozoa show for an appropriate glycolysable substrate at the end of capacitation: the metabolic shift occurs in the presence of pyruvate and fructose but the glycolytic pathway cannot be utilized until a suitable substrate is available. The fact that this decline in $\mathrm{O}_{2}$ consumption is observed both in the presence and absence of glucose provides evidence that this phenomenon is not an expression of the Crabtree effect, i.e. glucose-induced inhibition of respiration, as has been suggested for guinea-pig spermatozoa (Rogers et al., 1979).

In experiments similar to the present ones, Boell (1985) reported that the rate of $\mathrm{O}_{2}$ consumption by washed spermatozoa was constant during capacitation when cells were continuously monitored for $2-3 \mathrm{~h}$. However, the washing procedure removes a surface-associated inhibitory factor and consequently washed spermatozoa are immediately fertile and retain full functional competence for at least $2 \mathrm{~h}$ (Fraser, 1984). Therefore, the observations of Boell (1985) are not directly 
relevant to metabolic activity during capacitation. Once the alteration in metabolic activity which accompanies capacitation has been effected, it is quite probable that the rate remains constant for some time.

It is pertinent to address briefly the argument presented by Boell (1985) that the requirement for a glycolysable substrate is essentially artefactual, with the limited $\mathrm{O}_{2}$ dissolved in the culture medium (due to the use of $5 \% \mathrm{O}_{2}-5 \% \mathrm{CO}_{2}-90 \% \mathrm{~N}_{2}$ ) forcing the spermatozoa to turn to the anaerobic glycolytic pathway. During the preincubation phase the consumed $\mathrm{O}_{2}$ can be at least in part replenished by diffusion of $\mathrm{O}_{2}$ from the equilibrated liquid paraffin overlay into the medium. More importantly, however, the functional assessment demonstrating this specific requirement involves a 10-fold dilution of sperm suspension into fresh medium and thus $\mathrm{O}_{2}$ depletion should not be a factor. Furthermore, although fertilization can only be assessed readily after about $1 \mathrm{~h}$, the glucose-evoked responses in the spermatozoa themselves, i.e. induction of both the acrosome reaction and hyperactivated motility, occur within $5 \mathrm{~min}$ and in direct response to glucose; neither pyruvate nor lactate will substitute for glucose (Fraser \& Quinn, 1981). In the present study some replicates were carried out in the presence of $5 \% \mathrm{CO}_{2}$ in air $\left(21 \% \mathrm{O}_{2}\right)$ and others in the $\mathrm{O}_{2}-\mathrm{CO}_{2}-$ $\mathrm{N}_{2}$ mixture. The pattern of $\mathrm{O}_{2}$ consumption was the same in both gas phases.

All experimental assessments in Series II-IV were made in media which contained glucose but were modified in other ways so as to compromise fertilizing ability. Two of the modifications also affected the rate of capacitation, with - $\mathrm{Ca}$ medium retarding it and hyperosmotic high $\mathrm{Na}$ medium accelerating it. All 3 modified media, including iso-osmotic high $\mathrm{K}$ medium which does not interfere with capacitation per se, inhibit fertilizing ability (Fraser, 1982, 1983, 1987). $\mathrm{O}_{2}$ consumption measured under these same conditions consistently increased during 120 min incubation, despite the presence of glucose. Therefore alterations in medium composition which inhibit functional ability also prevent the downward shift in oxidative metabolism. However, changes in composition which allow expression of fertilizing potential promote the metabolic shift. Not only that, they do so at a time consistent with the onset of functional competence, e.g. at both 30 and $120 \mathrm{~min}$ for conditions which accelerate capacitation but only at $120 \mathrm{~min}$ for those which retard or have no effect on capacitation rate. While it is true that the sperm concentrations used for $\mathrm{O}_{2}$ electrode monitoring were higher than those routinely used for fertilization studies, successful fertilization has been achieved with similarly high concentrations (Fraser \& Drury, 1975). Therefore, there is no reason to believe that the samples might be intrinsically different.

Deutch et al. (1985) reported that $\mathrm{O}_{2}$ consumption by human spermatozoa increased significantly when their concentration fell below 1.5-2.5 $\times 10^{7}$ cells $/ \mathrm{ml}$. Thus, comparisons between suspensions of very different cell densities may prove to be invalid. In the present study all suspensions within a replicate were prepared from the same males, often from the same suspension, and the sperm concentration in all replicates was quite similar with a mean of $1.4 \times 10^{7}$ cells $/ \mathrm{ml}$. Therefore, it was felt that these comparisons were indeed valid.

Data obtained from the assessment of mammalian spermatozoa after incubation in utero (see 'Introduction') or in vitro in the presence of female reproductive tract fluids (Foley \& Williams, 1967; Black et al., 1968; Iritani et al., 1969; Spilman et al., 1970; Stone et al., 1973) indicate an increase in oxidative metabolism with time rather than a decrease as found in the present study. However, it may be that these results are not as discordant as they initially appear. Analyses of female reproductive tract fluids have revealed that their ionic composition often differs considerably from that of blood, e.g. elevated $\mathrm{K}^{+}$at $\sim 20-30 \mathrm{mM}$ compared with $\sim 5 \mathrm{~mm}$ for blood (Borland et al., 1977, 1980; Johnson \& Overstreet, 1982) and at least some of the earlier studies were carried out in the presence of such fluids. Despite the fact that capacitation in vivo occurs in these fluids, Fraser (1983) has demonstrated that elevated $\mathrm{K}^{+}$inhibits fertilization in the mouse. Since a reduction in $\mathrm{K}^{+}$leads to immediate egg penetration if spermatozoa have been incubated long enough for complete capacitation, she has suggested that localized alterations in $\mathrm{K}^{+}$concentration within the oviduct may represent a mechanism to modulate fertilizing potential in vivo. In the present study, these same conditions were shown to affect significantly the pattern of $\mathrm{O}_{2}$ 
consumption and elevated $\mathrm{K}^{+}$concentrations, similar to those found in female tract fluids, promoted an increase in consumption with time, i.e. a result consistent with the other studies cited here. However, these mouse sperm suspensions proved to be non-fertilizing and the same may have been true for spermatozoa of those species examined in earlier studies. Certainly there is evidence that extracellular $\mathrm{K}^{+}$-related effects can be mediated via glycolysis (discussed by Fraser, 1983), an important consideration when glycolysis plays a central role in sperm function.

The above discussion is not intended to suggest that a decline in oxidative metabolism necessarily occurs in all mammalian species. Mouse spermatozoa are unusual in relying totally on a glycolysable substrate, but most spermatozoa require a glycolysable substrate, in addition to pyruvate and lactate, at some point in capacitation to achieve optimal function, e.g. rat (Tsunoda \& Chang, 1975; Niwa \& Iritani, 1978), hamster (Bavister \& Yanagimachi, 1977; Dravland \& Meizel, 1981), and human (Hoshi et al., 1982). The exception is the guinea-pig for which inclusion of glucose retards the acrosome reaction, compared to medium containing only pyruvate and lactate (Rogers \& Yanagimachi, 1975). A re-evaluation of metabolic activity, using defined culture media, in spermatozoa from species other than the mouse is required to resolve the question.

In conclusion, $\mathrm{O}_{2}$ consumption declines with time in mouse suspensions incubated in a glucosecontaining medium which promotes both capacitation and fertilization. If suspensions are incubated in conditions which, despite the presence of glucose, inhibit fertilization, the pattern observed is one of an increase with time but this can be reversed by altering the medium composition to one that permits expression of fertilizing ability. Mouse spermatozoa require glycolysable substrate to fertilize eggs and this pattern of $\mathrm{O}_{2}$ consumption suggests that a shift from oxidative phosphorylation to glycolysis may accompany the onset of functional ability. The extracellular ionic composition, by affecting intracellular metabolic pathways, may play an important role in modulating sperm function.

M.L. was the recipient of an MRC Intercalated Award. We thank Andrew Osborne for preparing the artwork. This study was supported in part by a grant from the AFRC.

\section{References}

Bavister, B.D. \& Yanagimachi, R. (1977) The effects of sperm extracts and energy sources on the motility and acrosome reaction of hamster spermatozoa in vitro. Biol. Reprod. 16, 228-237.

Bedford, J.M. (1970) Sperm capacitation and fertilization in mammals. Biol. Reprod., Suppl. 2, 128-158.

Black, D.L., Crowley, L.V., Durby, R.T. \& Spilman, C.H. (1968) Oviduct secretion in the ewe and the effect of oviduct fluid on oxygen uptake by ram spermatozoa in vitro. J. Reprod. Fert. 15, 127-130.

Boell, E.J. (1985) Oxygen consumption of mouse sperm and its relationship to capacitation. J. exp. Zool. 234, 105-116.

Boell, E.J. \& Burkus, J.K. (1984) Oxygen consumption and motility of mouse sperm as affected by oxidizable substrates and oxygen tension. Carlsberg Res. Commun. 49, 147-154.

Borland, R.M., Hazra, S., Biggers, J.D. \& Lechene, C.P. (1977) The elemental composition of the environments of the gametes and preimplantation embryo during initiation of pregnancy. Biol. Reprod. 16, 147-157.

Borland, R.M., Biggers, J.D., Lechene, C.P. \& Taymor, M.L. (1980) Elemental composition of fluid in the human Fallopian tube. J. Reprod. Fert. 58, 479-482.
Deutch, D.S., Katz, D.F. \& Overstreet, J.W. (1985) Increases in human sperm oxygen consumption at low cell concentrations. Biol. Reprod. 32, 865-871.

Dravland, E. \& Meizel, S. (1981) Stimulation of hamster sperm capacitation and acrosome reaction in vitro by glucose and lactate and inhibition by the glycolytic inhibitor $\alpha$-chlorohydrin. Gamete Res. 4, 515-523.

Foley, C.W. \& Williams, W.L. (1967) Effect of bicarbonate and oviduct fluid on respiration of spermatozoa. Proc. Soc. exp. Biol. Med. 126, 634637.

Fraser, L.R. (1982) $\mathrm{Ca}^{2+}$ is required for mouse sperm capacitation and fertilization in vitro. J. Androl. 3, $412-419$.

Fraser, L.R. (1983) Potassium ions modulate expression of mouse sperm fertilizing ability, acrosome reaction and whiplash motility in vitro. J. Reprod. Fert. 69, $539-553$.

Fraser, L.R. (1984) Mouse sperm capacitation in vitro involves loss of a surface-associated inhibitory component. J. Reprod. Fert. 72, 373-384.

Fraser, L.R. (1987) Minimum and maximum extracellular $\mathrm{Ca}^{2+}$ requirements during mouse sperm capacitation and fertilization in vitro. J. Reprod. Fert. 81, $000-000$.

Fraser, L.R. \& Drury, L.M. (1975) The relationship 
between sperm concentration and fertilization in vitro of mouse eggs. Biol. Reprod. 13, 513-518.

Fraser, L.R. \& Lane, M. (1986) Oxygen consumption by epididymal mouse sperm incubated under fertilizing and non-fertilizing conditions. Develop. Growth and Differ. Suppl. 123, 89, Abstr.

Fraser, L.R. \& Quinn, P.J. (1981) A glycolytic product is obligatory for initiation of the sperm acrosome reaction and whiplash motility required for fertilization in the mouse. J. Reprod. Fert. 61, 25-35.

Hamner, C.E. \& Williams, W.L. (1963) Effect of the female reproductive tract on sperm metabolism in the rabbit and fowl. J. Reprod. Fert. 5, 143-150.

Hoppe, P.C. (1976) Glucose requirement for mouse sperm capacitation in vitro. Biol. Reprod. 15, 39-45.

Hoshi, K., Saito, A., Suzuki, M., Hayashi, K. \& Yanagimachi, R. (1982) Effects of substrates on penetration of human spermatozoa into zona pellucida of human eggs and the zona-free hamster eggs. Jpn. J. Fert. Steril. 27, $439-444$.

Iritani, A., Gomes, W.P. \& VanDemark, N.L. (1969) The effect of whole, dialyzed and heated female genital tract fluids on respiration of rabbit and ram spermatozoa. Biol. Reprod. 1, 77-82.

Johnson, L.L. \& Overstreet, J.W. (1982) Potassium and pyruvate may be regulators of rabbit oviductal sperm motility. Biol. Reprod., Suppl. 1, 26, 145A, Abstr.

Mounib, S. \& Chang, M.C. (1964) Effect of in utero incubation on the metabolism of rabbit spermatozoa. Nature, Lond. 201, 943-944.
Murdoch, R.N. \& White, I.G. (1967) The metabolism of labelled glucose by rabbit spermatozoa after incubation in utero. J. Reprod. Fert. 14, $213-223$.

Niwa, K. \& Iritani, A. (1978) Effect of various hexoses on sperm capacitation and penetration of rat eggs in vitro. J. Reprod. Fert. 53, 267-271.

Rogers, B.J. \& Yanagimachi, R. (1975) Retardation of guinea pig sperm acrosome reaction by glucose: the possible importance of pyruvate and lactate metabolism in capacitation and the acrosome reaction. Biol. Reprod. 13, 568-575.

Rogers, B.J., Chang, L. \& Yanagimachi, R. (1979) Glucose effect on respiration: possible mechanism for capacitation in guinea pig spermatozoa. J. exp. Zool. 207, 107-112.

Siegel, S. (1956) Nonparametric Statistics for the Behavioral Sciences. McGraw-Hill Kogakusha Ltd, Tokyo.

Spilman, C.H., Duby, R.T. \& Black, D.L. (1970) Effect of intrauterine device on sheep oviduct fluids: chemical composition and stimulation of spermatozoa respiration in vitro. Biol. Reprod. 3, 7681.

Stone, R.T., Foley, C.W., Thorne, J.G. \& Huber, T.L. (1973) Effect of oviductal fluids on oxidative phosphorylation in spermatozoa. Proc. Soc. exp. Biol. Med. 142, 64-67.

Tsunoda, Y. \& Chang, M.C. (1975) In vitro fertilization of rat and mouse eggs by ejaculated sperm and the effect of energy sources on in vitro fertilization of rat eggs. J. exp. Zool. 193, 79-86.

Received 23 January 1987 